Military Technical College

Kobry El-Kobbah,

Cairo, Egypt

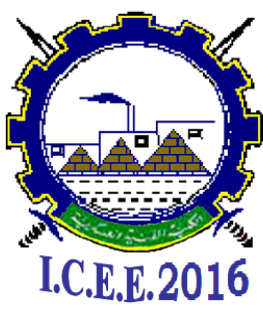

$8^{\text {th }}$ International Conference

on

Chemical \& Environmental

Engineering

$19-21$ April 2016

\title{
CBP-3
}

\section{Environmental Air Pollution Control by New Egyptian Ward El Nile Based Filter}

\author{
Elham F. Mohamed ${ }^{a}$, Sohair A. Sayed Ahmed ${ }^{\mathrm{b}}$, Nasser M. Abdel-Latif ${ }^{\mathrm{a}}$ and Asmaa EL \\ Mekawy $^{\mathrm{a}}$
}

\begin{abstract}
Air pollution is a complex problem involving particles, asbestos, gaseous contaminants, aldehydes and volatile organic compounds. Indoor air pollution is a very real and dangerous problem because indoor air is typically 2 to 5 times more polluted than the outdoor air (EPA publication, Indoor Air Quality, 2003). Indoor air pollutants not only cause discomfort but also can cause diseases by its accumulation, such as respiratory $\&$ heart diseases, asthma and cancer. It's estimated that 2.2 million deaths each year are due to indoor air pollution. Indoor air pollution problem is more complicated on developing countries than on developed ones due to fuel combustion (such as wood, charcoal and animal dung) is burned inside homes for cooking and heating. Therefore, indoor air quality improvement is paid more and more attention to preserve human health and the environment. A major aim in the air pollution control is finding economic ways of treating gas containing low levels of pollutants.

The present study is directed to provide an economic activated carbon air purifier that can conveniently installed with small volume and has high gas contaminants removal efficiency. The air purifier made from activated carbon prepared in our laboratory at National Research Center using Ward El Nile (Water Hyacinth) as raw material through chemical activation. This aspect has two benefits: the first one is presenting a technology that aims to recycle and disposal Ward El Nile (water hyacinth) and solving the problem of this water plant. The second benefit is producing cheap and local porous structure activated carbon with high surface area $\left(\mathrm{S}_{\mathrm{BET}}, 1100 \mathrm{~m}^{2} / \mathrm{g}\right)$. The results showed that the total mesoporous and microporous volumes of the prepared AC were 0.230 and $0.113 \mathrm{~cm}^{3}$, respectively. The performance test of the new air purifier filter for $\mathrm{SO}_{2}$ gas removal from kitchen indoor air environment indicated that the new filter has high $\mathrm{SO}_{2}$ adsorption removal efficiency $(90 \%)$.

In particular, the present filter concerns in promoting the development of an economically feasible air purifier system (hundred percent manufacturing in Egypt) capable of eliminating odors, Volatile Organic Compounds (VOCs) and other indoor air contaminants at ambient temperature with saving the energy consuming.
\end{abstract}

Key words: Air pollution, Environmental Protection, Ward El Nile, Activated carbon.

${ }^{a}$ Air Pollution Department, Division of Environmental Research, National Research Centre, Giza, Egypt; ${ }^{b}$ Physical Chemistry Department, Division of Inorganic Industries and Mineral Resources, National Research Centre, 33 EL Bohouth St., Dokki, Giza, P.O.12622, Egypt; Tel.: 33335494, Fax: 33370931; e-mail: elham_farouk0000@yahoo.com 
Military Technical College

Kobry El-Kobbah,

Cairo, Egypt

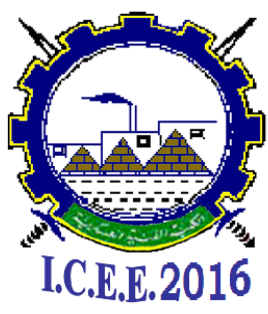

$8^{\text {th }}$ International Conference

on

Chemical \& Environmental

Engineering

$19-21$ April 2016

\section{Introduction}

Ward El Nile (water hyacinth) is a free floating water plant. It has been called the world's worst invasive aquatic weed and is continuously creating environmental problems. The plant extremely rapid proliferation and overcrowd growth present serious challenges in navigation, irrigation and power generation. Water hyacinth causes many problems including blocking irrigation channels and impeding the flow of water in large rivers. It may also have adverse effects on human health by enabling the breeding of mosquitoes, bilharzias and other human parasites. In addition, water hyacinth affects the water quality by reducing water temperature, $\mathrm{pH}$, bicarbonate content and increasing biological oxygen demand and free carbon dioxide. It may also reduce water nutrients level which ultimately makes water remarkably less useful for livestock and humans. The flowers of water hyacinth were first seen wild in the River Nile in Egypt in the 1890s. Prior to the construction of the Aswan Dam, the main Nile channel was relatively free of water hyacinth, as the annual floods flushed it downstream. The presence of the dam caused the flow of water to be much slower, and water hyacinth found its way into the irrigation and drainage canals fed by the Nile. In Egypt, people are highly dependent on the River Nile for transportation, fishing, drinking and tourism. Introducing water hyacinth in the River Nile has resulted in severe socio-economic problems. For example, El-Sawaf $(1998 \mathrm{a}, \mathrm{b})$ reported that water lost due to the presence of water hyacinth in the River Nile branching channels and drainage system was about 47,523,000 $\mathrm{m}^{3}$ /year. Exploring new ways of water hyacinth treatment, disposal and utilization is very important for solving its significant problem. Attempts to mechanically and manually control the plant reproduction were proven to be costly and results were negligible. The possible uses of water hyacinth include: (1) Biogas plants, heating, lighting and generation of electricity (Ofoefulel et al., 2009); (2) Composting units (ADESINA et al., 2011); (3) Animal/fish food (Aboud et al., 2005); (4) Using dried water hyacinth stems to make crafts, furniture and writing paper (De Groote et al., 2003); (5) Phytoremediation agent and bio-sorbent for several heavy metals and other pollutants (Mahamadi and Nharingo, 2010a, b). Growing concerns about the environment have resulted in the development of new environmental technologies, new materials, and new ways to reduce; minimize and solve the environmental wastes problem. Consequently, many research works have been carried out with the main objective of utilizing water hyacinth especially that the plant has shown considerable ability to absorb and concentrate many toxic metals from aquatic environments.

On the other hand, indoor air quality (IAQ) remains a very important issue today because it can significantly affect people's health, comfort satisfaction and productivity. The health effects of indoor air pollution are important because individuals spend large fractions of their time in indoor environments and frequently have little control over exposure time or indoor air quality (IAQ). Exposure to air contaminants such as the gaseous byproducts (sulfur dioxide, $\mathrm{SO}_{2}$; nitrogen dioxide, $\mathrm{NO}_{2}$; ozone, $\mathrm{O}_{3}$ ) and the volatile organic compounds (VOCs) has been a recent subject of concern because of the prevalence of these compounds in indoor as well as outdoor environments and because of their adverse health effects. They include 
Military Technical College

Kobry El-Kobbah,

Cairo, Egypt

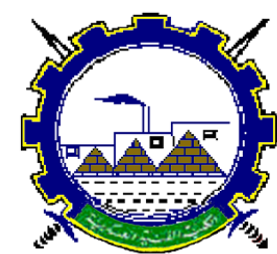

I.C.E.E.2016 $8^{\text {th }}$ International Conference

on

Chemical \& Environmental

Engineering

$19-21$ April 2016

aliphatic and aromatic hydrocarbons, chlorinated hydrocarbons, various ketones, acetaldehydes, and formaldehyde. Many technologies for indoor air treatments have been developed during the last years such as bio-oxidation and adsorption (Mohamed et al., 2015b).

Activated carbon adsorption is an effective technology for environmental remediation, industrial processing and to remove trace contaminants from both air and water in general. Its economical drawback has stimulated the interest to utilize cheaper raw materials for the production of activated carbon (Mohamed et al., 2011). Consequently, a wide variety of agricultural by-products and wastes have been investigated as cellulosic precursors for the production of activated carbon. Due to the high carbon content of water hyacinth and its ubiquity, preparing activated carbon from water hyacinth can help in utilizing the plant for air and water treatment purposes.

The present study aimed to encourage the valorization and recycle water hyacinth by producing activated carbon via chemical activation process. Another goal of the research study was to establish the technical and economic feasibility of adsorption technology, providing a new filter system for the first time to remove the indoor air contaminants in Egypt at ambient temperature and at low cost.

\section{Materials and Methods}

\subsection{Reagents}

All chemicals used were analytical grade reagents supplied by Sigma Aldrich. Phosphoric acid, Methylene Blue (MB), Sodium tetra chloromercurate, Mercuric chloride and Sodium chloride were used.

\subsection{Collection of Ward EI Nile}

Ward El Nile (water hyacinth) samples have been collected from the River Nile (CairoEgypt). Samples have been washed with boiled water to remove dust and other impurities, airdried in sunlight until all moisture was evaporated, cut into short pieces and crushed to coarse grains.

\subsection{Preparation of Activated Carbon from water hyacinth}

In this study, the activated carbon was produced through the chemical activation process. $50 \mathrm{~g}$ of the dried raw materials were treated with $50 \%$ analytical grade phosphoric acid for $24 \mathrm{hr}$ and then separated by decantation. The impregnated raw material was transported to a stainless steel tubular furnace system admitted to a controller temperature (Fig. 1). The 
Military Technical College

Kobry El-Kobbah,

Cairo, Egypt

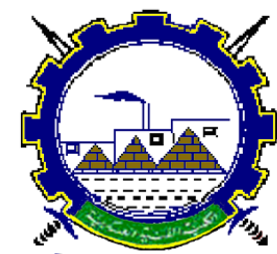

I.C.E.E.2016 $8^{\text {th }}$ International Conference

on

Chemical \& Environmental

Engineering

$19-21$ April 2016

soaked sample was firstly heated at $170^{\circ} \mathrm{C}$ at a rate of $10^{\circ} \mathrm{C} / \mathrm{min}$ and kept at this temperature for $30 \mathrm{~min}$ to remove water. The activation temperature was then raised slowly until $500^{\circ} \mathrm{C}$ with a heating rate of $10^{\circ} \mathrm{C} / \mathrm{min}$ under its own atmosphere for $2 \mathrm{hr}$. The produced carbon was cooled and then it was subjected to thorough washing with hot water until neutral $\mathrm{pH}$. Then the samples were dried in an oven at $110^{\circ} \mathrm{C}$ overnight.

\subsection{Characterization of prepared activated carbon}

\subsubsection{Specific surface area and pore volume}

Surface area of the water hyacinth based activated carbon (WHAC) was determined using nitrogen as the sorbate at $77 \mathrm{~K}$ in a static volumetric apparatus (Quantachrome NOVA Automated Gas Sorption System). Specific total surface areas were calculated using the BET equation.

\subsubsection{Fourier Transform Infrared Spectroscopy (FTIR) analysis}

A known mass $(1 \mathrm{mg})$ of water hyacinths based activated carbon was grinded and milled with $100 \mathrm{mg} \mathrm{KBr}$ to form a fine powder. This powder was then compressed into a thin pellet under 7 tons for 5 minutes. The sample was analyzed using spectrometer and the spectrum was recorded in a spectral range.

\subsubsection{Adsorption isotherm of Methylene blue by the prepared activated carbon}

The adsorption capacity of the prepared activated carbon was investigated by batch adsorption experiment of Methylene Blue (MB). $100 \mathrm{~mL}$ of MB solution of various initial concentrations were agitated with $0.05 \mathrm{~g}$ of the prepared activated carbon into several small flasks using water bath shaker at $25 \mathrm{C}^{\circ}$ for $72 \mathrm{hr}$ to attain equilibrium concentration. Then, solutions were filtered and MB concentrations were measured using a UV/VIS spectrophotometer (NOVASPEC 4049 Spectrophotometer LKB BIOCHROM) at $625 \mathrm{~nm}$.

\subsection{Removal of sulfur dioxide from indoor air by WHAC air purifier}

The new WHAC air purifier (EG patent, application number 2015/1979) made from activated carbon prepared in our laboratory at National Research Center using water hyacinth as raw material through chemical activation. The performance of this air purifier filter was investigated for $\mathrm{SO}_{2}$ removal from a kitchen indoor air environment. The indoor air samples from kitchen area were collected during cooking times from a house situated in Helwan industrial area. The choice of Helwan area due to the fact that sulfur dioxide $\left(\mathrm{SO}_{2}\right)$ is one of the major emitted pollutants in Helwan from several air pollution sources (motor vehicles exhaust, power generation and industrial activities). Samples were collected by drawing air with constant flow (1L/ min for 24 hours) through bubbler containing absorbance solution for $\mathrm{SO}_{2}$. The indoor air samples had been collected before and after using the new air purifier filter. 
Military Technical College

Kobry El-Kobbah,

Cairo, Egypt

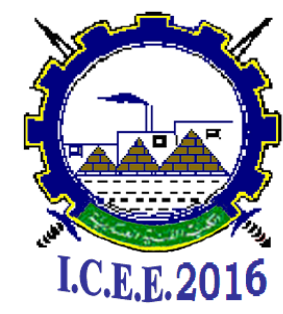

$8^{\text {th }}$ International Conference

on

Chemical \& Environmental

Engineering

$19-21$ April 2016

\subsubsection{Sulfur dioxide determination method}

The concentration of sulfur dioxide was determined colorimetrically using West and Geake method (Harrison and Perry, 1986). The method sensitivity is reported to be in the range of 0.005 to $5 \mathrm{ppm} \mathrm{SO}_{2}$ in air. Sulfur dioxide gas was collected from the kitchen indoor by using a glass bubbler sampler containing $50 \mathrm{~mL}$ of absorbing solution $(0.1 \mathrm{M}$. Sodium Tetrachloromercurate) with constant flow (1L/min for 24 hours). Acid bleaching pararosaniline hydrochloride solution and dilute aqueous formaldehyde were added to the complex ion. Samples were measured using an ultraviolet/visible (UV/VIS) spectrophotometer (NOVASPEC 4049 Spectrophotometer LKB BIOCHROM) at $560 \mathrm{~nm}$.

\section{Results and Discussion}

\subsection{Characterization of the activated carbon}

Figure 2 shows $\mathrm{N}_{2}$ adsorption -desorption isotherms of water Hyacinth activated carbon at $77 \mathrm{~K}$. The first part of the isotherm represents micropores and the second part at high relative pressure is due to multilayer adsorption in mesopores. The BET surface area $\left(\mathrm{S}_{\mathrm{BET}}\right)$ of the prepared AC was about $1100 \mathrm{~m}^{2} / \mathrm{g}$. Pore size distribution of the prepared water Hyacinth activated carbon by density functional theory is represented in Figure 3. It was noticed that two different peaks at $15 \mathrm{~nm}$ and $35 \mathrm{~nm}$ correspond to the micropore and mesopore, respectively. The total mesoporous and microporous volumes of the prepared AC were 0.230 and $0.113 \mathrm{~cm}^{3} / \mathrm{g}$, respectively. FTIR analysis was carried out to identify the functional groups present in the prepared activated carbon surface. FTIR analysis showed the presence of phenols, carboxyl and carbonyl groups. Functional surface groups affect the adsorption mechanism of the activated carbon (Zheng et al., 2014). The prepared activated carbon exhibits carbonyl functional groups $\left(\mathrm{C}=\mathrm{O}\right.$ at $\left.1740 \mathrm{~cm}^{-1}\right)$. The bands observed in the range of 1000 to $1260 \mathrm{~cm}^{-1}$ indicating C-O single bond of the carboxylic acids and alcohols. The prepared activated carbon exhibits also hydroxyl functional groups, including hydrogen bonding $\left(\mathrm{O}-\mathrm{H}\right.$, stretching at 3000-3500 $\left.\mathrm{cm}^{-1}\right)$.

\subsection{Methylene blue adsorption studies}

The adsorption capacity of WHAC for MB was represented in Figure 4. The results indicated that WHAC has a maximum dye adsorption elimination capacity of $45 \mathrm{mg} / \mathrm{g}$. This proved that the prepared activated carbon is mesoporous since the methylene blue is used to characterize mesoporous activated carbons. Mohamed et al. (2015a) reported that the sugarcane bagasse-based activated carbon was used successfully as adsorbing agents for the removal of $\mathrm{MB}$ dye (around 90\%) from aqueous solutions. The isotherms of MB adsorption were evaluated according to the major two parameter models, Langmuir and Freundlich. The isotherms of MB adsorption were evaluated according to the major two parameter models, Langmuir model which is given by equation (1) and Freundlich model which is given by equation (2). 
Military Technical College

Kobry El-Kobbah,

Cairo, Egypt

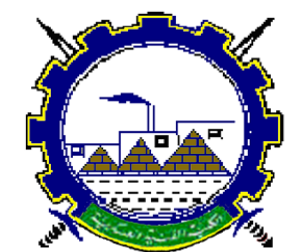

I.C.E.E.2016 $8^{\text {th }}$ International Conference

on

Chemical \& Environmental

Engineering

$19-21$ April 2016

$$
q_{\mathrm{e}}=\frac{q_{\max } \cdot K_{\mathrm{L}} \cdot C_{\mathrm{e}}}{1+K_{\mathrm{L}} \cdot C_{\mathrm{e}}},
$$

\section{Where:}

$\mathrm{q}_{\mathrm{e}}$ is the amount of adsorbed MB on the prepared activated carbon at equilibrium $\left(\mathrm{mg} \cdot \mathrm{g}^{-1}\right), \mathrm{C}_{\mathrm{e}}$ is the concentration of the $\mathrm{MB}$ at equilibrium $\left(\mathrm{mg} \cdot \mathrm{L}^{-1}\right), \mathrm{q}_{\max }$ is the maximum adsorption capacity $\left(\mathrm{mg} \cdot \mathrm{g}^{-1}\right)$, and $\mathrm{K}$ is the adsorption intensity or Langmuir coefficient $\left(\mathrm{L} \cdot \mathrm{mg}^{-1}\right)$.

$$
q_{\mathrm{e}}=K_{\mathrm{F}} \cdot C_{\mathrm{e}}^{1 / \mathrm{n}}
$$

Where $\mathrm{K}_{\mathrm{F}}$ is the Freundlich constant and $n$ is related to the magnitude of the adsorption driving force and to the adsorbent site energy distribution.

From the correlation coefficient values $\left(\mathrm{R}^{2}=0.998\right.$ and 0.997 , for Langmuir and Freundlich model, respectively) and from Figure $5 \mathrm{a}, \mathrm{b}$ it is noticed that the experimental adsorption isotherms fit very well to the Langmuir model. The maximum adsorption capacity, $\mathrm{q}_{\max }$ and the adsorption equilibrium constant, $\mathrm{K}$ are obtained from the intercept and the slope of the linearized form of Langmuir isotherm model, respectively. The values of different parameters of Langmuir adsorption model at $25 \mathrm{C}^{\circ}$ for $\mathrm{MB}$ on the prepared activated carbon are as follows: $\mathrm{q}_{\max }=45.5 \mathrm{mg} \cdot \mathrm{g}^{-1}$ and $\mathrm{K}=3.84 \mathrm{mg}$. $\mathrm{L}^{-1}$.

\subsection{Performance of WHAC for sulfur dioxide Removal from indoor air}

The performance of WHAC air purifier for the $\mathrm{SO}_{2}$ removal is depicted in Figures 6 and 7 . Figure 6 shows that $\mathrm{SO}_{2}$ concentration in kitchen indoor gas concentration after using WHAC filter decreased to $0.344 \mu \mathrm{g} / \mathrm{m}^{3}$ as compared to the kitchen indoor gas concentration before using the filter $\left(3.99 \mu \mathrm{g} / \mathrm{m}^{3}\right)$ in the first day (24hr of filter application). In the second exposure day, the $\mathrm{SO}_{2}$ concentration values in the treated and untreated samples were approximately the same that obtained in the first day $\left(3.44\right.$ and $0.356 \mu \mathrm{g} / \mathrm{m}^{3}$, respectively). In the third treatment, the results showed that the $\mathrm{SO}_{2}$ concentrations in both samples were slightly lower than that in the previous treatments. This result can be explained by the fact that $\mathrm{SO}_{2}$ gas concentration depend on the human activities during the study. The results illustrated in Figure 7 indicated that the filter removal efficiency by studying the difference in $\mathrm{SO}_{2}$ concentration before and after using the filter. The results showed that more than $90 \%$ $\mathrm{SO}_{2}$ removed in the first treatment by filter. Similarly, Akbar et al. (2013) reported that the adsorption of $\mathrm{SO}_{2}$ onto commercial activated carbon produced from coal was found to be $100 \%$. Iyobe et al. (2004) also cited that ammonia removal efficiency by granular activated carbon was $80 \%$ at $20 \mathrm{C}$. The removal efficiency in the second and third using of WHAC filter was slightly decreased to $89 \%$. This high removal percentage of the filter indicated that 
Military Technical College

Kobry El-Kobbah,

Cairo, Egypt

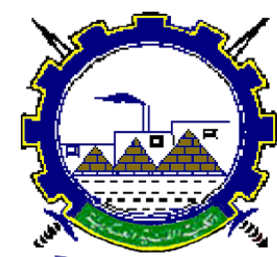

I.C.E.E.2016 $8^{\text {th }}$ International Conference

on

Chemical \& Environmental

Engineering

$19-21$ April 2016

it is still capable of removing additional $\mathrm{SO}_{2}$ gas. Consequently, the performance of WHAC air purifier in the field-scale shows that the filter is effective as indoor air adsorbent treatment system.

\section{Conclusions}

This research work proves the effectiveness of water hyacinths activated carbon prepared by using chemical activation process. The WHAC has BET surface area $\left(\mathrm{S}_{\mathrm{BET}}\right)$ of $1100 \mathrm{~m}^{2} / \mathrm{g}$ and the total mesoporous and microporous volumes of WHAC are 0.230 and $0.113 \mathrm{~cm}^{3} / \mathrm{g}$, respectively.

For economic cost, it was assumed that there is a considerable cost differential between the production costs of activated carbon from water hyacinth by chemical activation and the selling price for the activated carbon in the commercial marketplace. Indeed, the adsorption capacity of the prepared activated carbon should be considered. Moreover, the economic significance of large scale production is also important. The low cost and high availability of water hyacinth would be minimized the manufacture costs.

The economic water hyacinth activated carbon air purifier (EG patent application number 2015/1979) can conveniently installed with small volume and has high gas contaminants removal efficiency. The performance test of the new air purifier filter for $\mathrm{SO}_{2}$ gas removal from kitchen indoor air environment indicated that the new filter has high $\mathrm{SO}_{2}$ adsorption removal efficiency $(90 \%)$. The $\mathrm{SO}_{2}$ removal results confirmed that the new WHAC air purifier can be used as an effective applicable filter for treating a variety of gas pollutants from the indoor environment.

\section{Acknowledgement}

The authors are grateful to National Research Centre, for providing laboratory facilities towards successful completion of this work.

\section{References:}

[1] Aboud, R.S. Kidunda, J. Osarya, Potential of water hyacinth (Eicchornia crassipes) in ruminant nutrition in Tanzania, Livest. Res. Rural (2005) 5-17. [http://www.log1.net/search/lrrd//rrd17/8/abou17096.htm (Published 5 August 2005)].

[2] El-Sawaf, An annular type jet pump model for floated weed and water hyacinth removal, Proceeding of 3 rd International Water Technology Conference, IWTC 98, Alexandria, (1998 a) 423-435.

[3] El-Sawaf, Two-peripheral nozzles jet pump model for weed control, Port Said Engineering Research Journal 2 (198b) No. 1.

[4] A Joint EPA Working Paper from ENERGY STAR and Indoor Air Quality September 2003. 
Military Technical College

Kobry El-Kobbah,

Cairo, Egypt

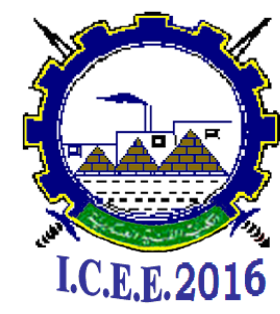

$8^{\text {th }}$ International Conference

on

Chemical \& Environmental

Engineering

$19-21$ April 2016

[5] C.Mahamadi and T. Nharingo, Utilization of water hyacinth weed (Eichhorniacrassipes) for the removal of $\mathrm{Pb}(\mathrm{II}), \mathrm{Cd}(\mathrm{II})$ and $\mathrm{Zn}$ (II) from aquatic environments: an adsorption isotherm study, Environ.Technol. 31 (2010a) 1221-1228.

[6] C.Mahamadi and T. Nharingo, Competitive adsorption of $\mathrm{Pb}$ (II), $\mathrm{Cd}$ (II) and $\mathrm{Zn}$ (II) ions onto EichhorniaCrassipesin Binary and Ternary systems, Bioresour. Technol.101 (2010b) 859-864.

[7] E.F. Mohamed, C. Andriantsiferana, A.M. Wilhelm and H. Delmas, Competitive adsorption of phenolic compounds from aqueous solution using sludge-based activated carbon, Environ. Technol.32 (2011) 1325-1336.

[8] E. F. Mohamed, M. A. El-Hashemy, N. M. Abdel-Latif and W. H. Shetaya, Production of sugarcane bagasse-based activated carbon for formaldehyde gas removal from potted plants exposure chamber, Journal of the Air \& Waste Manage. Assoc. 65 (2015a) 1413-1420.

[9] E. F. Mohamed, G. Awad, C. Andriantsiferana and A. I. El- Diwany, Biofiltration technology for the removal of toluene from polluted air using Streptomyces griseus, Environ.Technol.(2015b)DOI:10.1080/09593330.2015.1107623, To link to this article: http://dx.doi.org/10.1080/09593330.2015.1107623

[10] G. O.Adesina, W. B. Akanbi, O. S. Olabode and O. Akintoye, Effect of water hyacinth and neem based composts on growth, fruit yield and quality of cucumber (Cucumissativus), African J. Agricultural Res. 6 (2011) 6477-6484.

[11] M. Harrison and R. Perry, Handbook of Air Pollution Analysis, Chapman and Hall, London, New York, 2nd edition (1986).

[12] H.De Groote, O. Ajuonu, S. Attignon, R.Djessou and P.Neuenschwander, Economic impact of biological control of water hyacinth in Southern Benin, Ecol Eco. 45 (2003) 105-113.

[13] U. Ofoefule, E. O. Uzodinma and O. D. Onukwuli, Comparative study of the effect of different pretreatment methods on biogas yield from water Hyacinth

(Eichhorniacrassipes), Inter. J. Phys. Sci. 4 (2009) 535-539.

[14] S. Akbar, K. Chew, N. Ismail and T. Padmesh, Adsorption of Gaseous Pollutants $\left(\mathrm{SO}_{2}\right.$ \& CO) onto Palm Shell Activated Carbon, EURECA, Engineering undergraduate research catalyst conferences 1-2 July 2013.

[15] T.Iyobe, T. Asada, K. kawata and K. Oikawa, Comparison of removal efficiencies for ammonia and amine gases between woody charcoal and activated carbon, J. Health Sci. 50 (2004) 148-153.

[16] X.Zheng, X.Jin, W. Zhenzhen and L.Weihao, Removal of iron and manganese in steel industry drainage by biological activated carbon, Desalination and water treatment. (2014) www.destwater.com doi: 10.1080/19443994.2014-963682. 
Military Technical College Kobry El-Kobbah, Cairo, Egypt

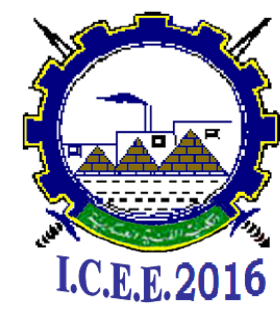

$8^{\text {th }}$ International Conference on

Chemical \& Environmental Engineering

$19-21$ April 2016

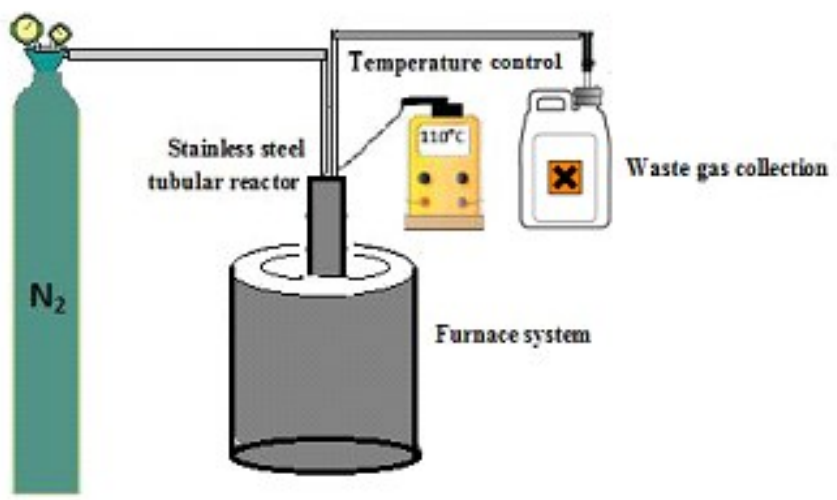

Figure 1. Diagram of the stainless steel tubular furnace system used for the preparation of activated carbon from water hyacinth

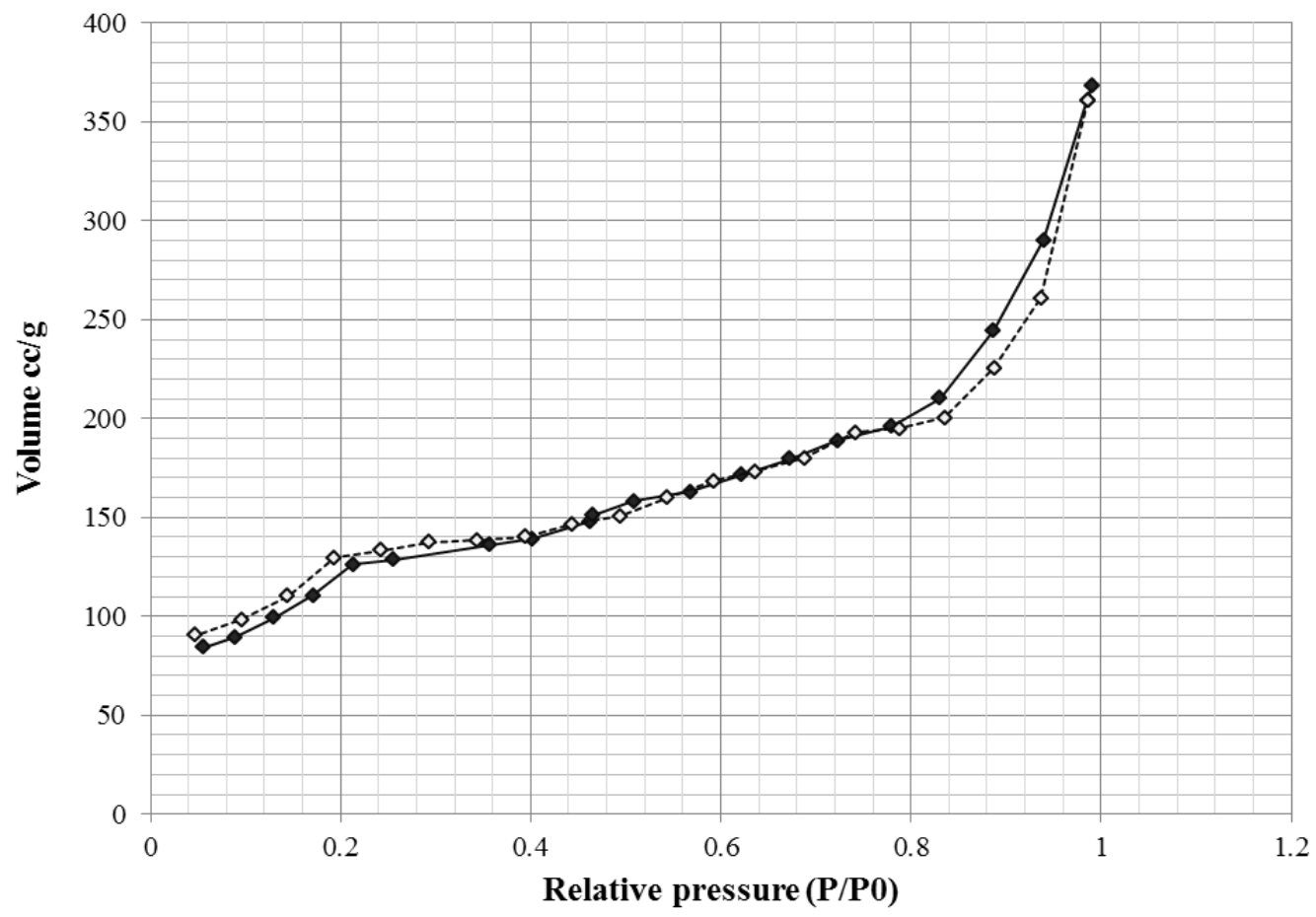

Figure 2. Adsorption-desorption isotherm of $\mathrm{N}_{2}$ of the prepared WHAC at $77 \mathrm{~K}$. 
Military Technical College Kobry El-Kobbah,

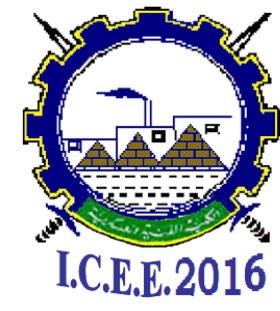

$8^{\text {th }}$ International Conference on

Chemical \& Environmental Engineering

$19-21$ April 2016

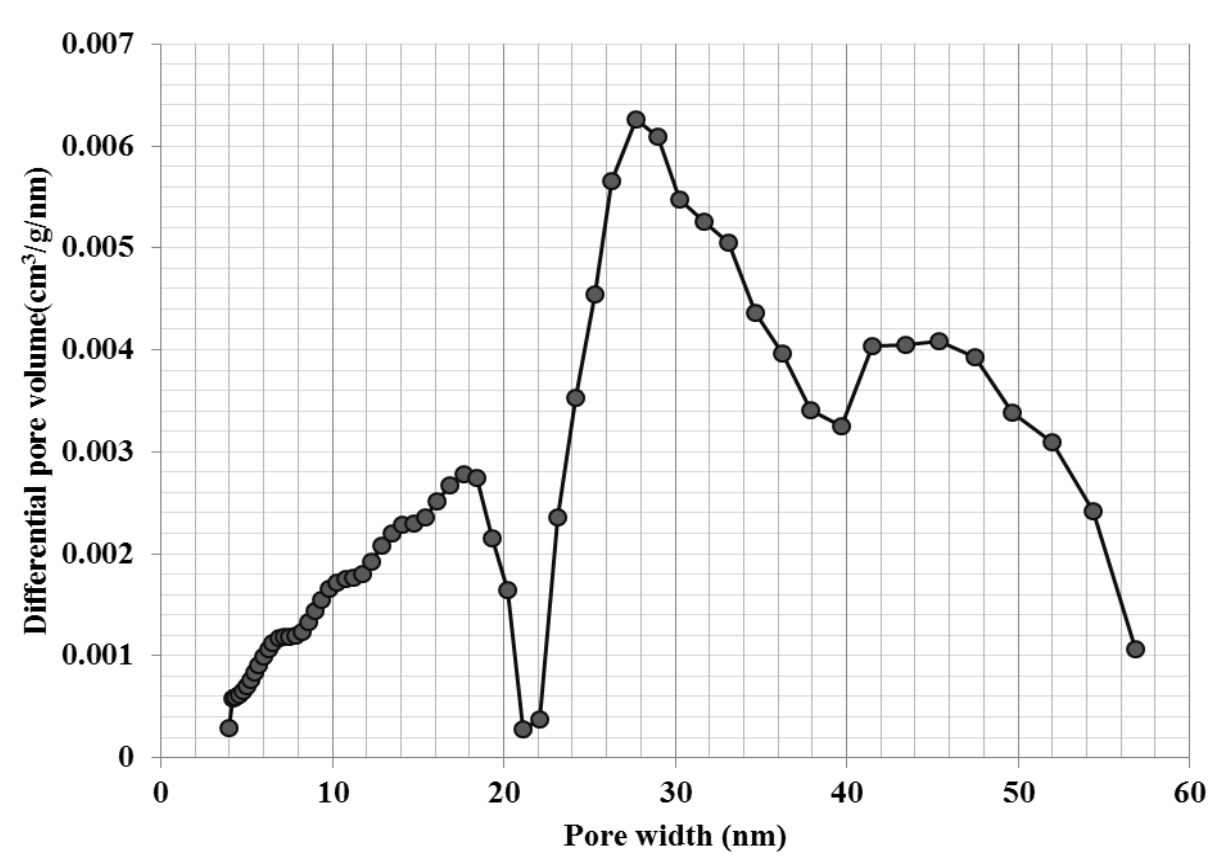

Figure 3. Pore size distribution of the prepared WHAC determined by density functional theory.

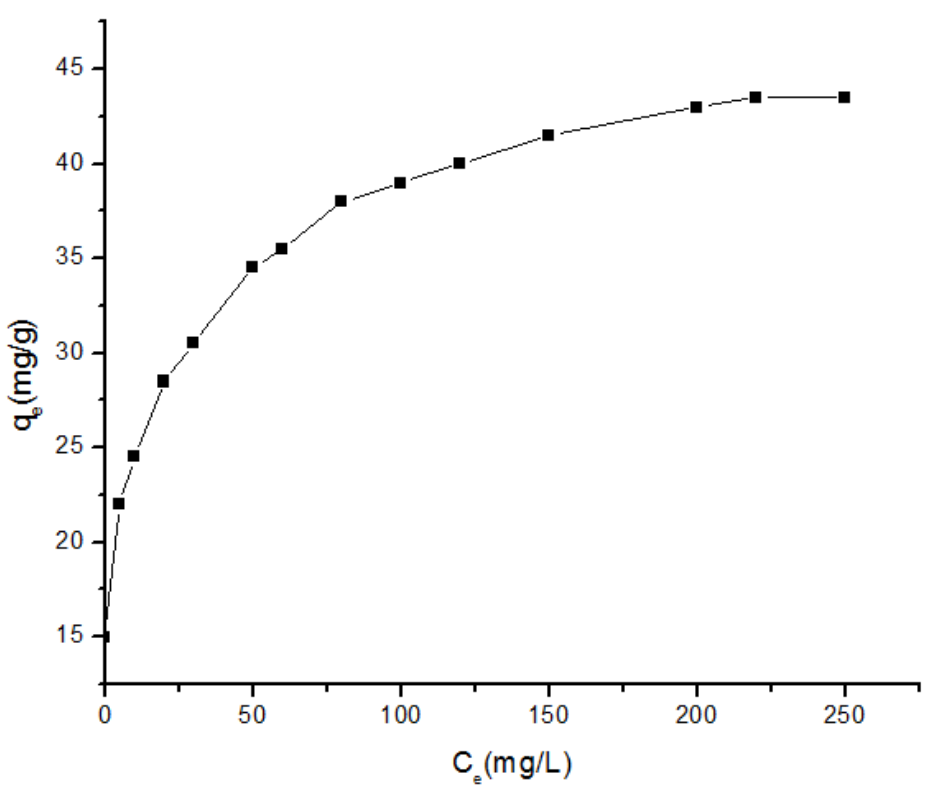

Figure 4. Adsorption isotherm of Methylene Blue using WHAC at $25^{\circ} \mathrm{C}$ 
Military Technical College Kobry El-Kobbah, Cairo, Egypt

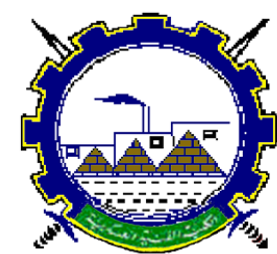

I.C.E.E.2016 $8^{\text {th }}$ International Conference on

Chemical \& Environmental Engineering

$19-21$ April 2016
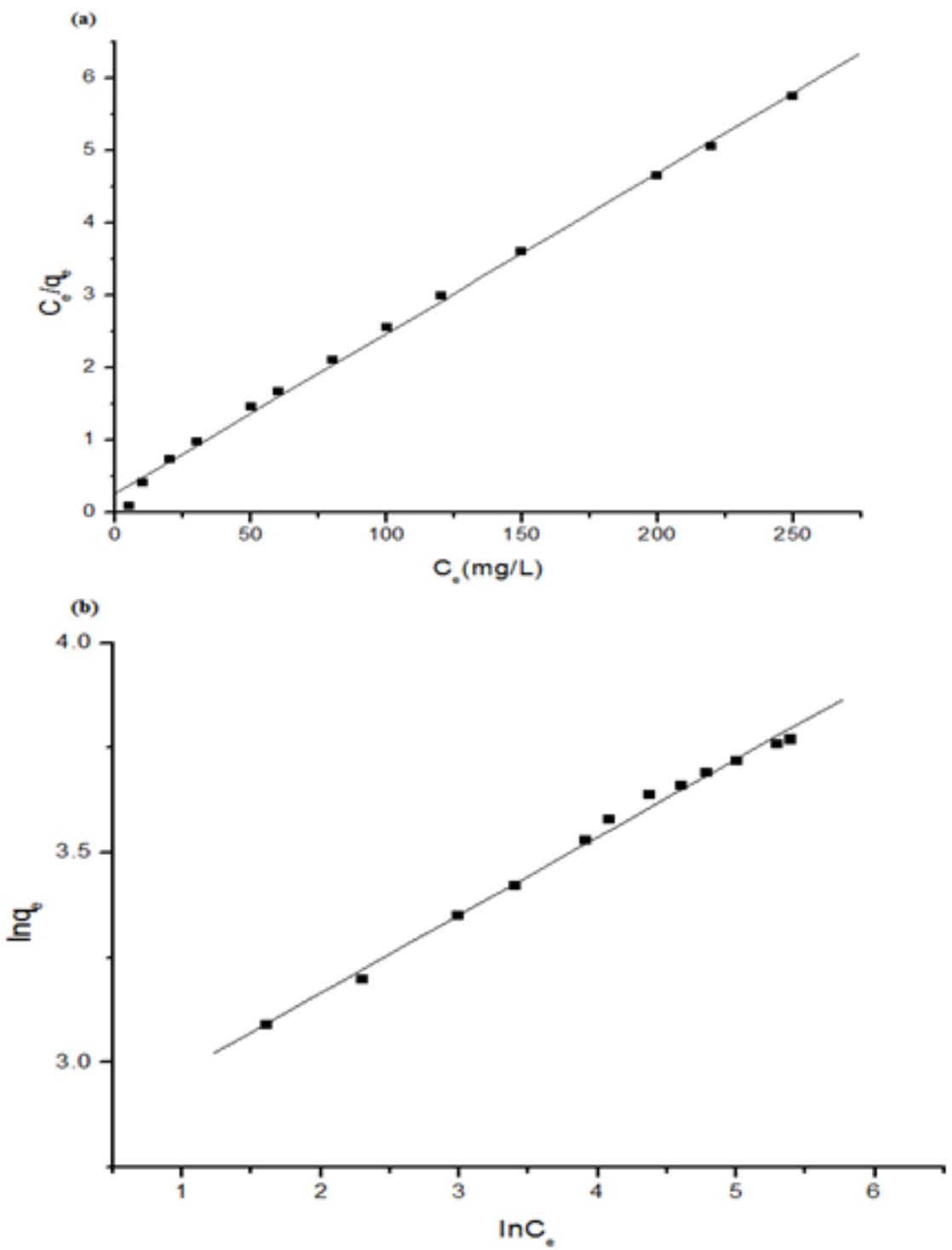

Figure 5. Langmuir isotherm (a) and Freundlich isotherm (b) for MB adsorption of WHAC 
Military Technical College Kobry El-Kobbah,

Cairo, Egypt

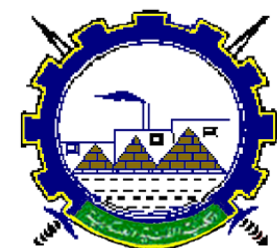

I.C.E.E.2016 $8^{\text {th }}$ International Conference

on

Chemical \& Environmental

Engineering

$19-21$ April 2016

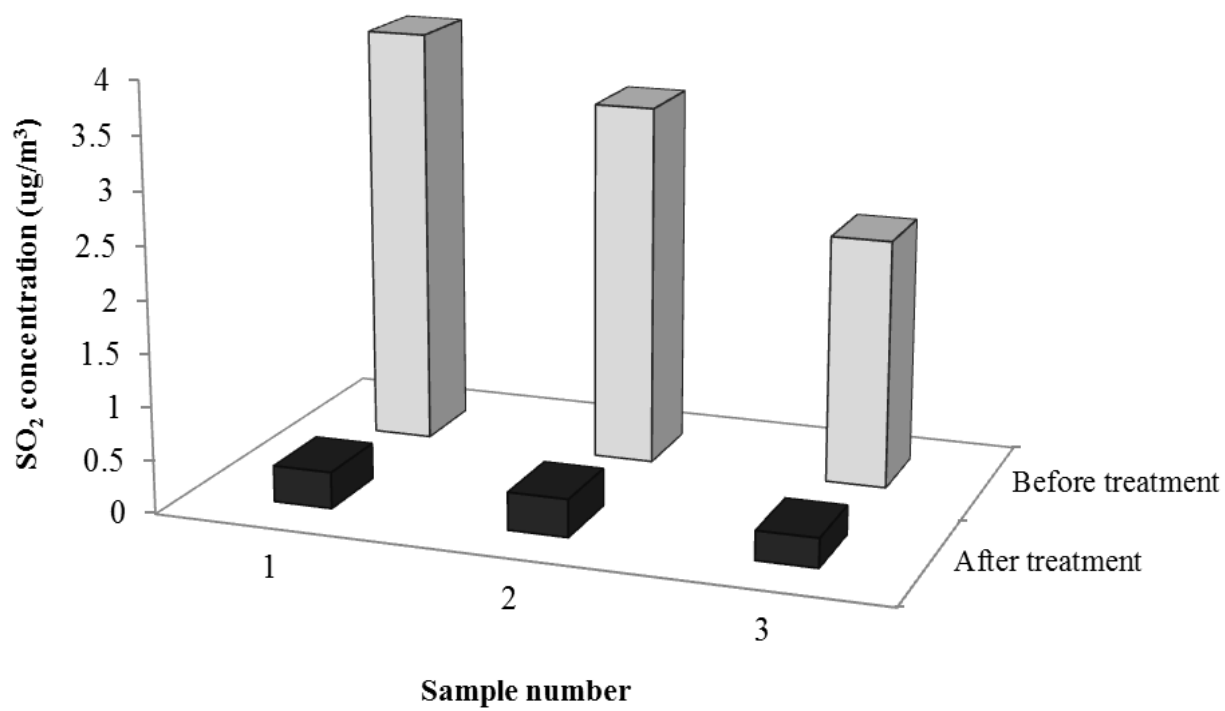

Figure 6. $\mathrm{SO}_{2}$ gas concentration in the kitchen indoor air with and without WHAC filter

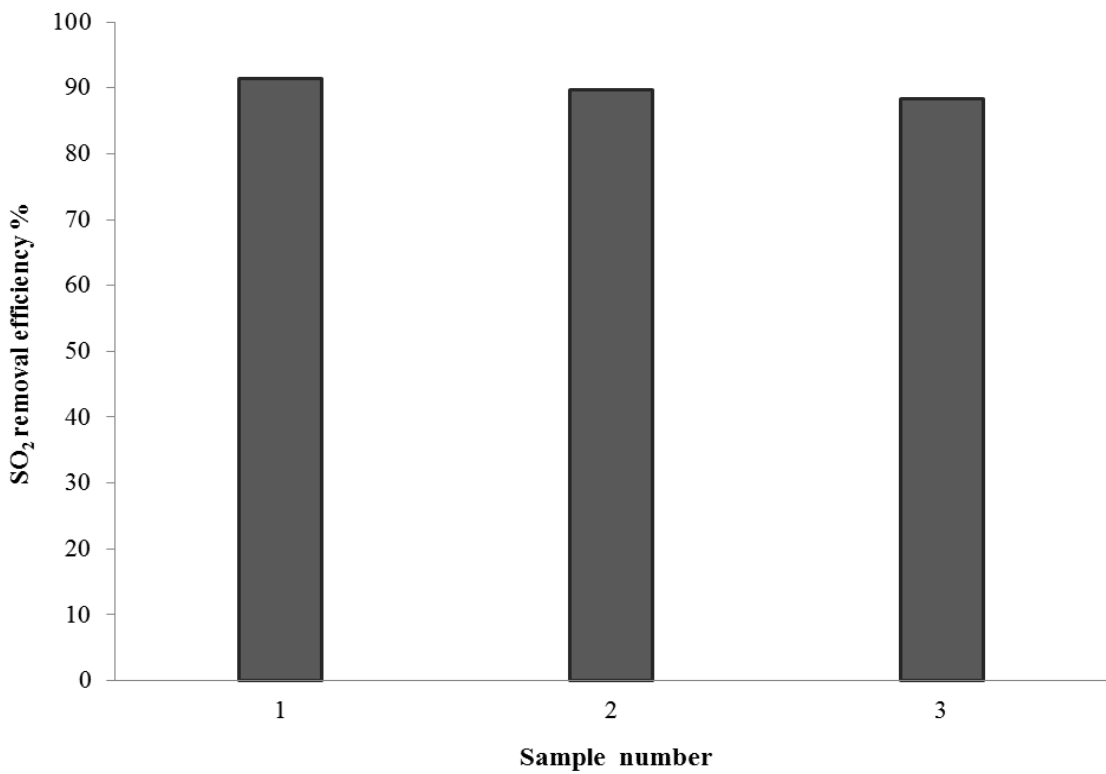

Figure 7. $\mathrm{SO}_{2}$ removal efficiency by using the new WHAC air purifier filter 